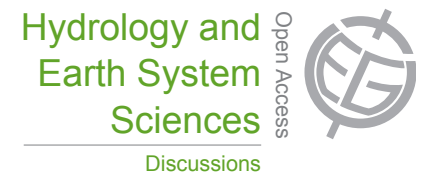

This discussion paper is/has been under review for the journal Hydrology and Earth System Sciences (HESS). Please refer to the corresponding final paper in HESS if available.

\section{Temporal stability of soil moisture patterns measured by proximal ground-penetrating radar}

\author{
J. Minet ${ }^{1,{ }^{*}}$, N. E. C. Verhoest $^{2}$, S. Lambot ${ }^{1}$, and M. Vanclooster ${ }^{1}$ \\ ${ }^{1}$ Earth and Life Institute, Université catholique de Louvain, Croix du Sud 2 BP 2 , \\ 1348 Louvain-la-Neuve, Belgium \\ ${ }^{2}$ Laboratory of Hydrology and Water Management, Ghent University, Coupure links 653, \\ 9000 Gent, Belgium \\ now at: Université de Liège, Arlon Campus Environnement, Avenue de Longwy 185, \\ 6700 Arlon, Belgium
}

Received: 26 February 2013 - Accepted: 18 March 2013 - Published: 3 April 2013

Correspondence to: J. Minet (julien.minet@ulg.ac.be)

Published by Copernicus Publications on behalf of the European Geosciences Union.

\section{HESSD}

10, 4063-4097, 2013

Temporal stability of soil moisture

patterns

J. Minet et al.

Title Page

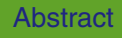

Introduction

Conclusions

References

Tables

Figures

14

$\rightarrow 1$

4

Back

Close 


\section{Abstract}

We analyzed the temporal stability of soil moisture patterns acquired using a proximal ground-penetrating radar (GPR) in a 2.5 ha agricultural field at five different dates over three weeks. The GPR system was mounted on a mobile platform, allowing for 5 real-time mapping of soil moisture with a high spatial resolution $(2-5 \mathrm{~m})$. The spatiotemporal soil moisture patterns were in accordance with the meteorological data and with soil moisture measurements from soil core sampling. Time-stable areas showing the field-average moisture could be revealed by two methods: (1) by the computation of temporal stability indicators based on relative differences of soil moisture to the fieldaverage and (2) by the spatial intersection of the areas showing the field-average. Locations where the mean relative difference was below $0.02 \mathrm{~m}^{3} \mathrm{~m}^{-3}$ extended up to $10 \%$ of the field area whereas the intersection of areas showing the field-average within a tolerance of $0.02 \mathrm{~m}^{3} \mathrm{~m}^{-3}$ covered $5 \%$ of the field area. Compared to most of the previous studies about temporal stability of soil moisture, time-stable areas and their spatial

Surface soil moisture, i.e. the water held in the upper few centimeters of soils, is an important state variable of the water cycle and climate system. It is increasingly used by the hydrology and climate science community as a direct or proxy variable to be assimilated into hydrological (Pauwels et al., 2002; De Lannoy et al., 2007; Crow and Ryu, 2009) and global circulation models (Seneviratne et al., 2010), especially owing to the ongoing development of dedicated remote sensing platforms for surface soil moisture
HESSD

10, 4063-4097, 2013
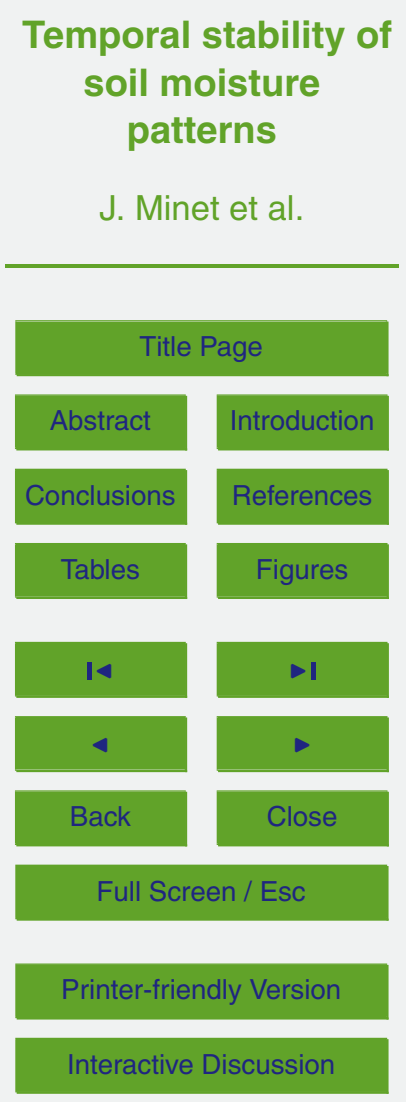
measurements. Exposed to the rapidly changing atmospheric conditions, surface soil moisture is known to be highly variable in time and space at practically all scales of interest. A better understanding of the surface soil moisture dynamics could be obtained based on the analysis of spatio-temporal soil moisture measurements.

5 In that respect, the characterization of surface soil moisture patterns may benefit from the temporal stability of the spatial patterns of soil moisture, a concept firstly introduced by Vachaud et al. (1985). The investigation of the temporal stability of soil moisture patterns has then received a specific attention in numerous experimental soil moisture field studies (e.g. Brocca et al., 2009; da Silva et al., 2001; Jacobs et al., 2004; 10 Guber et al., 2008; Grayson and Western, 1998; Mohanty and Skaggs, 2001). These studies showed that when repeating measurements of soil moisture over a certain extent, it often resulted in similar spatial patterns. In particular, locations that persistently show the field-average could be found with different degrees of accuracy and stability with time.

15 A first application of temporal stability of soil moisture studies is the selection of timestable locations for the installation of in-situ sensors or for the optimal sampling of soil moisture measurements (Heathman et al., 2012). Although temporal stability studies have mainly focused on the retrieval of time-stable point-locations showing the fieldaverage, the temporal stability of the continuous soil moisture pattern is also needed for many applications. In that respect, one may be interested in finding time-stable locations either exhibiting the field-average or extreme soil moisture values. If the offsets between time-stable locations showing under- or over-estimates and the field-average are known, these locations can be also used to determine the field-average (Starks et al., 2006).

25 Rather than the temporal stability of point-locations, knowing the temporal stability of soil moisture patterns can better help for the validation of remote sensing data (e.g. Cosh et al., 2004), downscaling of remotely-sensed soil moisture data (e.g. Loew and Mauser, 2008; Vernieuwe et al., 2011) and support hydrological modeling at the field scale, given the high sensitivity of hydrological models to soil moisture. When studying
HESSD

$10,4063-4097,2013$
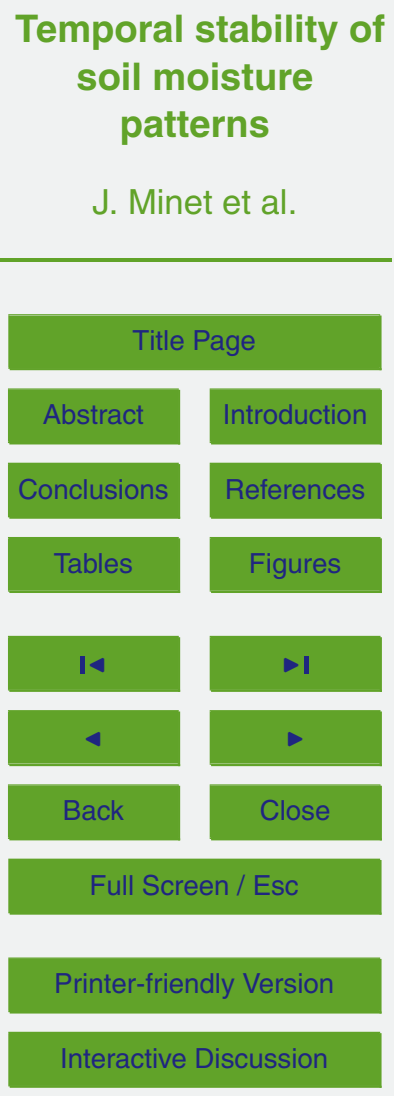
a catchment, the persistence of soil moisture patterns in time can bring out the spatial pattern of hydrological processes such as infiltration, surface redistribution and uprising groundwater that are occurring in the field.

The concept of temporal stability implies that soil moisture is partly locally deter5 mined by soil or topographic attributes that are time-invariant. In that respect, Mittelbach and Seneviratne (2012) proposed a new statistical approach for decomposing time-invariant and time-dependant contributions of the spatial variance of absolute soil moisture, but this requires long-term soil moisture measurements. At the field scale, soil moisture spatial patterns are mostly controlled by topography, soil type, vegetation and 10 land use. The relative predominance of these controlling factors is variable and also dependent on the wetness conditions, e.g. as shown by Grayson et al. (1997) for different catchments in Australia where spatial patterns of soil moisture switched between a dry and a wet state because different hydrological processes took place according to the wetness conditions. The assumption that topography is the first prevalent fac15 tor has been largely supported in many hydrological studies (e.g. Hawley et al., 1983; Güntner et al., 2004; Western et al., 1999) and is the basis of numerous hydrologic models and indices, such as the widely-used TOPMODEL (Beven and Kirkby, 1979) and the topographic wetness index (Quinn et al., 1995). In that respect, Grayson and Western (1998) showed that time-stable locations representing the field-average were located in mid-slopes areas, which was further confirmed in the works of Brocca et al. (2009); Jacobs et al. (2004); Mohanty and Skaggs (2001). Nevertheless, topography is not always the prevalent factor, either in case of dry conditions that may limit the lateral redistribution of water (Grayson et al., 1997), in case of flat topography (e.g. Hupet and Vanclooster, 2002) or when other factors dominate because of their large variability or their importance for a particular catchment. In that respect, in a highly contrasted field in terms of texture, da Silva et al. (2001) stated that clay content and organic matter were the main determining factors controlling soil moisture, whereas topographic attributes did not appear to be related to soil moisture. Soil properties showing time-stability appeared to be more site-specific and no general rule about soil properties that caused
HESSD

$10,4063-4097,2013$

Temporal stability of soil moisture patterns

J. Minet et al.

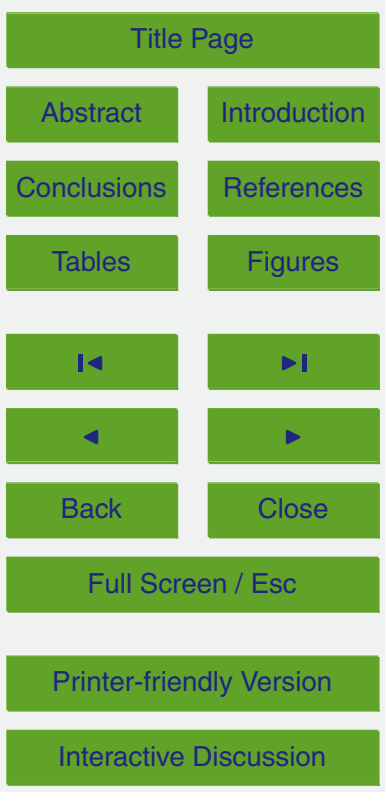


temporal stability of soil moisture could be drawn. For instance, while Jacobs et al. (2004) observed that sampling points with moderate or moderately high clay content tended to have more temporal stability, Mohanty and Skaggs (2001) noticed that sandy loams showed more temporal stability than silt loams. The importance of controlling 5 factors for temporal stability of soil moisture is dependent on the relative dominance of the factors that govern soil moisture patterns.

The characterization of soil moisture spatial patterns actually depends on the measurement scale, which is determined by the soil moisture measurement technique. According to Blöschl and Sivapalan (1995), the measurement scale can be character10 ized by a scale triplet that consists of extent, spacing and support scale. The extent is the total coverage of the measurements, the spacing (or resolution) is the distance between two measurements and the support (or integration, sampling scale) is the scale on which one measurement is integrated. Each soil moisture measurement technique can thus be characterized by its scale triplet. So far, the majority of the studies that have investigated the temporal stability of soil moisture patterns were built on soil moisture datasets acquired with small-scale invasive sensors (e.g. time domain reflectometry (TDR), capacitance probes, neutron probes or gravimetric sampling). These datasets are characterized by point measurements (small support scale) separated by large spacings over relatively small extents (field scale). On the other hand, remote sensing provides soil moisture data over large extents but with a spatial resolution that is usually too large for field-scale studies.

Proximal soil moisture sensing techniques, such as ground-penetrating radar (GPR), permit to perform high spatial resolution measurements at the field scale and to bridge the scale gap in terms of spatial resolution and support scale between invasive and remote sensors. Regarding time-stability studies, using proximal sensing techniques such as GPR allows to reveal time-stable areas and to investigate nearly-continuous spatial patterns instead of identifying time-stable points. In particular, the off-ground GPR method developed by Lambot et al. $(2004,2006)$ has shown great potential for soil moisture sensing and was applied in field conditions for proximal soil moisture
HESSD

$10,4063-4097,2013$

Temporal stability of soil moisture patterns

J. Minet et al.

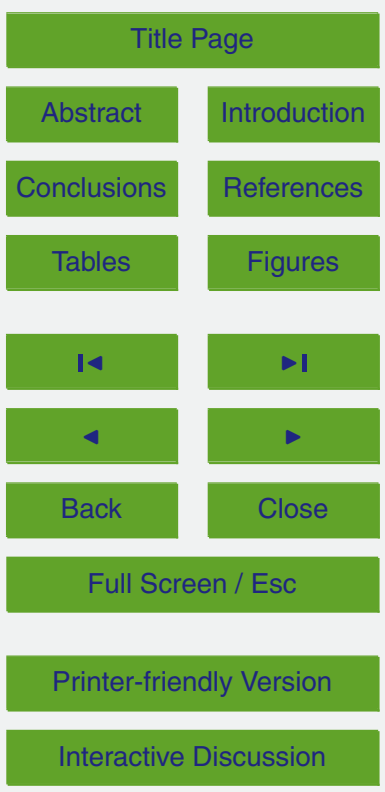


mapping by Jadoon et al. (2010); Jonard et al. (2011); Lambot et al. (2008); Minet et al. $(2011,2012)$. Soil permittivity and correlated water content are derived from inversion of a full-wave radar model that accounts for wave propagation in three-dimensional layered media and antenna effects, including antenna-soil interactions.

$5 \quad$ In this study, we used a large soil moisture dataset acquired with the proposed GPR method to investigate the spatiotemporal patterns of surface soil moisture and their temporal stability. Soil moisture was acquired in a 2.5 ha agricultural field at five different dates in spring 2010 in Belgium. First, soil moisture patterns and their evolution over time were investigated through a geostatistical analysis. Then, time-stable areas 10 showing the field-average were analyzed by two methods: (1) by the computation of temporal stability indicators based on the relative differences of soil moisture to the field-average (Vachaud et al., 1985) and (2) by the spatial intersection of the zones showing the field-average. The methods were compared in the light of the scale characteristics of the dataset.

\section{Materials and methods}

\subsection{Study site}

We surveyed a 2.5 ha agricultural field situated in the loess belt area in the center of Belgium (Lon. $4^{\circ} 41^{\prime} 8^{\prime \prime} \mathrm{E}$, Lat. $50^{\circ} 35^{\prime} 59^{\prime \prime} \mathrm{N}$ ) (Fig. 1). The soil type is uniformly silt loam and elevation ranges from $130 \mathrm{~m}$ to $144 \mathrm{~m}$ a.s.I. According to the national Belgian soil database (The Aardewerk database, Van Orshoven and Vandenbroucke, 1993), soil particle fractions are $4 \%$ of sand, $82 \%$ of silt and $14 \%$ of clay for a soil sampling point situated at about $500 \mathrm{~m}$ from the field. The GPR acquisitions were performed at the end of the winter at five different dates from 15 March to 6 April 2010. The field was covered by winter wheat having a canopy height less than $5 \mathrm{~cm}$. Meteorological data such as air temperature and precipitation were recorded with an hourly time step in a meteorological station situated at $2 \mathrm{~km}$ apart from the field (Fig. 2). Dry conditions characterized

Temporal stability of soil moisture patterns

J. Minet et al.

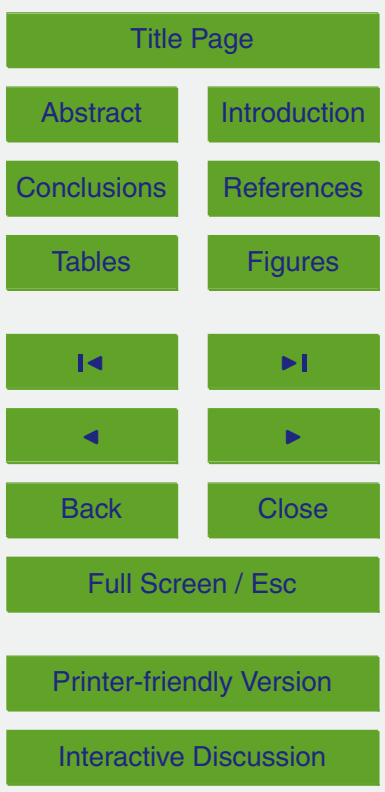


the first three dates of the acquisition while the last two dates were characterized by large antecedent precipitation events (Table 1).

\subsection{Soil moisture mapping by ground-penetrating radar}

The field was surveyed using a proximal off-ground GPR based on vector network an5 alyzer technology and a directive ultra-wideband horn antenna (Lambot et al., 2004, 2006). Similarly to the active radar remote sensing platforms, the GPR principle for soil moisture sensing is based on the measurement of an electromagnetic wave which is transmitted to the soil, backscattered by the soil surface and recorded by the GPR antenna. The backscattered electromagnetic wave is function of the soil dielectric permittivity. As the dielectric permittivity of water overwhelms the one of the soil particles and air, the propagation of the electromagnetic wave into the soil is mainly governed by its water content.

The soil dielectric permittivity was retrieved by inverting the GPR data using an electromagnetic model simulating the GPR wave propagation. The electromagnetic model is an exact solution of the 3-D Maxwell's equation for electromagnetic wave propagation in the air-soil system modeled as a planar layered medium. The full-wave inversion of the GPR data focused on the surface reflection in the time domain (Lambot et al., 2006), using GPR data in the frequency range $200-800 \mathrm{MHz}$ with a frequency step of $6 \mathrm{MHz}$. GPR-derived surface dielectric permittivity was then converted into volumetric soil moisture values using the relationship of Topp et al. (1980).

Field acquisitions were performed by mounting the GPR system on an all-terrain vehicle (ATV) equipped with a differential global positioning system (GPS) and a PC for automated acquisition, as used in Minet et al. (2012) (see Fig. 3). For each survey, the ATV followed 12 parallel tracks with a spacing of $5 \mathrm{~m}$ between the acquisition tracks 25 (see Fig. 1) and a driving speed of about $5 \mathrm{~km} \mathrm{~h}^{-1}$. The GPR horn antenna was situated at approximately $1.1 \mathrm{~m}$ above the ground surface, thereby providing a characterization footprint of about $2 \mathrm{~m}^{2}$ and a sampling depth around $5 \mathrm{~cm}$. This characterization depth is determined by the relatively low-frequency bandwidth of the GPR and is also slightly 4069
HESSD

10, 4063-4097, 2013

Temporal stability of soil moisture patterns

J. Minet et al.

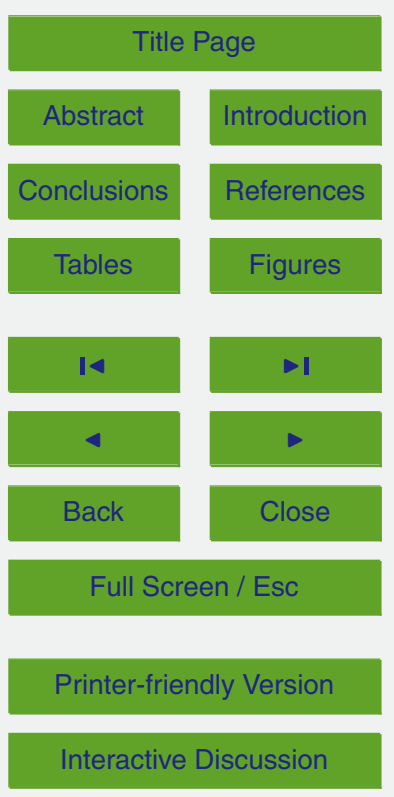


varying with the soil dielectric permittivity. Table 1 indicates the number of points and the duration of the acquisition for each survey. This proximal GPR method has an intermediate coverage between points measurements and continuous remote sensing acquisition. Compared to in situ soil moisture sensors, this method has a larger spa5 tial resolution but a lower temporal resolution. Soil moisture acquisition using this GPR setup was evaluated in Minet et al. (2012) in the same field and appeared to be precise (error of $0.0039 \mathrm{~m}^{3} \mathrm{~m}^{-3}$ ), accurate (RMSE of comparison with ground-truthing of $0.0233 \mathrm{~m}^{3} \mathrm{~m}^{-3}$ ) and repeatable (error of repetition of $0.0169 \mathrm{~m}^{3} \mathrm{~m}^{-3}$ ).

Some high soil permittivity values resulting in large soil moisture values were ob10 tained in particularly wet conditions in the last two surveys. These values were truncated at a maximum soil moisture of $0.5 \mathrm{~m}^{3} \mathrm{~m}^{-3}$, which is believed to be the soil moisture at saturation. These high values are expected to result from measurements over areas partly covered by ponding water.

In order to validate the accuracy of the GPR soil moisture measurements, surface soil moisture was independently measured by volumetric soil core sampling in the top $5 \mathrm{~cm}$ at 20 regularly spaced locations (see Fig. 1). Soil samples were oven-dried at $105^{\circ} \mathrm{C}$ for at least $48 \mathrm{~h}$ and the dry and wet weights were measured, in order to determine the volumetric soil moisture.

\subsection{Soil moisture interpolation}

20 Soil moisture maps were produced by the interpolation of point measurements using ordinary kriging. To deal with the uneven distribution of the points in space (i.e. approximately a $2 \mathrm{~m}$ spacing along the acquisition line and $5 \mathrm{~m}$ spacing between the lines), a rectangular neighborhood window was chosen such that the same number of points was taken in the perpendicular and parallel directions, respectively, with respect to the acquisition lines direction (Minet et al., 2012). This prevented acquisition line effects to appear in the interpolated maps. Unidirectional variograms estimates were computed along (parallel) the acquisition lines with a class distance from 0 to $150 \mathrm{~m}$ by a step of $5 \mathrm{~m}$ and were used for interpolating the point-data by kriging after fitting an exponential

\section{HESSD}

10, 4063-4097, 2013
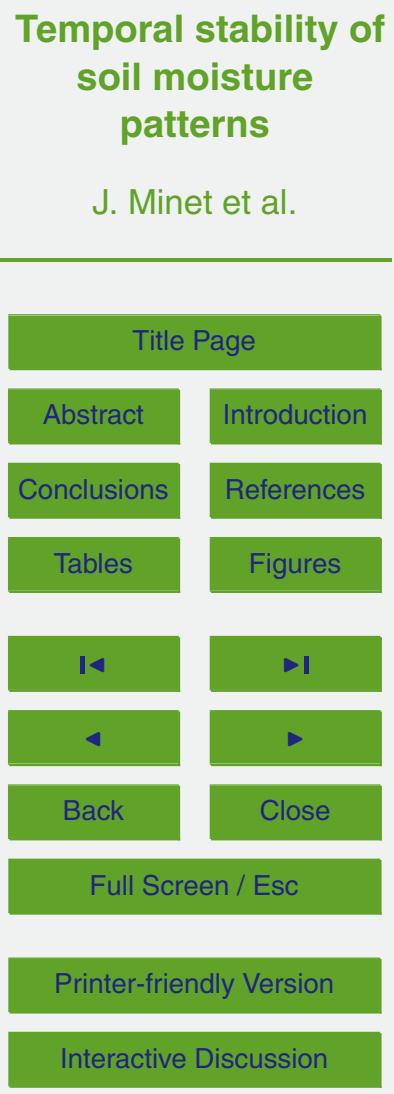

Interactive Discussion 
model accounting for a nugget effect. The exponential model appeared to be the best model for fitting the parallel variograms estimates for each survey.

The purpose of the interpolation was to allow the comparison between the 5 acquisitions, as the GPR measurements points could not be taken exactly at the same

5 locations, but along the same tracks. It is worth noting that the interpolation caused a smoothing of the measurements resulting in a reduction of the extremes values.

\subsection{Temporal stability of soil moisture pattern identification}

A large majority of studies that focused on the temporal stability of soil moisture at the field scale were based on point measurements. The GPR method resulted in a different characterization method compared to point measurements, with a much larger amount of data, a support scale close to the measurements spacing, but a rather low temporal sampling. Moreover, the GPR data could be interpolated owing to the high spatial sampling rate and in the aim of comparing the different acquisitions. Therefore, this study differed from previous ones since soil moisture patterns were compared instead of soil moisture points. In this study temporal stability was investigated using two methods: (1) using the widely-used time stability indicator developed by Vachaud et al. (1985) and (2) using an indicator based on the intersection of the areas showing the field-average.

In the first method, temporal stability was revealed by the computation, for each location $i$, of the mean and standard deviation over time of the relative differences in 20 soil moisture, $\bar{\delta}_{i}$ and $\sigma\left(\delta_{i}\right)$, respectively, which were firstly introduced by Vachaud et al. (1985) and widely used afterward (e.g. Brocca et al., 2009; Jacobs et al., 2004; Hu et al., 2010; Mohanty and Skaggs, 2001). These indicators are based on the relative

Temporal stability of soil moisture patterns

J. Minet et al.

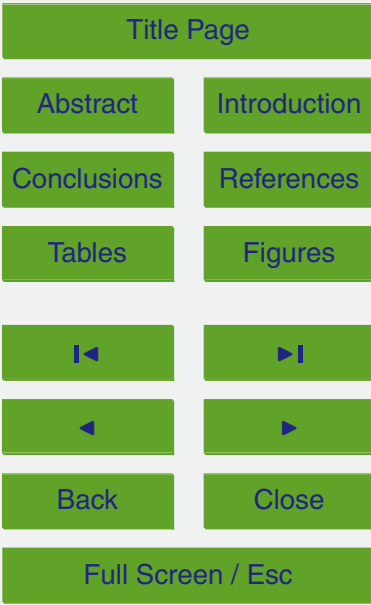

Printer-friendly Version

Interactive Discussion 
difference in soil moisture with the spatial average over time $(t)$ and are given by:

$\bar{\delta}_{i}=\frac{1}{n_{t}} \sum_{t=1}^{n_{t}} \frac{\theta_{i, t}-\bar{\theta}_{t}}{\bar{\theta}_{t}}$

HESSD

$\sigma\left(\delta_{i}\right)=\sqrt{\frac{1}{n_{t}-1} \sum_{t=1}^{n_{t}}\left(\frac{\theta_{i, t}-\bar{\theta}_{t}}{\bar{\theta}_{t}}-\bar{\delta}_{i}\right)^{2}}$

5 where $n_{t}$ being the number of dates and $\bar{\theta}_{t}$ the spatial average of soil moisture $\theta_{i, t}$ computed as follows:

$\bar{\theta}_{t}=\frac{1}{n_{i}} \sum_{i=1}^{n_{i}} \theta_{i, t}$

where $n_{i}$ is the number of locations within the field where soil moisture was interpolated.

The time-averaged mean of the relative difference $\bar{\delta}_{i}$ indicates, for each location, the difference in soil moisture with respect to the spatial average, i.e. whether the location is drier $\left(\bar{\delta}_{i}<0\right)$ or wetter $\left(\bar{\delta}_{i}>0\right)$ on average over time. Locations that on average over time show the spatial average of the field have $\bar{\delta}_{i}$ equal to zero. The standard deviation of the relative difference $\sigma\left(\delta_{i}\right)$ gives the degree of variation of the relative difference, that is, time-stable locations have low $\sigma\left(\delta_{i}\right)$. For identifying the most timestable locations for the spatial average, we may combine these indicators in a temporal stability indicator for the field-average $\mathrm{TSI}_{\delta_{i}}$ (Jacobs et al., 2004), which is given by:

$\mathrm{TSI}_{\delta_{i}}=\sqrt{\bar{\delta}_{i}^{2}+\sigma\left(\delta_{i}\right)^{2}}$

Temporal stability of soil moisture

patterns

J. Minet et al.

Title Page

Abstract

Introduction

Conclusions

References

Tables

Figures

14

Full Screen / Esc

Printer-friendly Version

Interactive Discussion 
The locations showing a high temporal stability for the field-average were thus given by the lowest $\mathrm{TSI}_{\delta_{i}}$ values, combining the mean difference of soil moisture compared to the field-average and its temporal standard deviation.

In the second method, time-stable locations showing the field-average were identified 5 by the intersection among the five dates of the zones where soil moisture was equal to the field-average within a tolerance of $\pm 0.02 \mathrm{~m}^{3} \mathrm{~m}^{-3}$. This threshold of $0.02 \mathrm{~m}^{3} \mathrm{~m}^{-3}$ was chosen as it is close to the soil moisture measurement and interpolation uncertainties (Minet et al., 2012). This method was expected to perform well for a relatively low number of acquisitions, as the intersected time-stable surface could only decreased with 10 further acquisitions. This method might be affected by a single date showing a different pattern. It is particularly well suited for comparing spatial patterns from proximal or remote sensing data because it benefits from the high spatial coverage of this type of data as compared to point measurements. A mathematical formulation of this method can be expressed as follows:

$15 \quad I_{i}=\prod_{t=1}^{n_{t}} \begin{cases}1 & \text { if }\left|\theta_{i, t}-\bar{\theta}_{t}\right|<0.02 \mathrm{~m}^{3} \mathrm{~m}^{-3} \\ 0 & \text { otherwise }\end{cases}$

where $I_{i}$ is a binary indicator showing if location $i$ is time-stable (1) or not (0).

\section{Soil moisture patterns}

\subsection{Geostatistical analysis}

Figure 4 shows the maps of the GPR-derived soil moisture point-measurements for the five surveys. Soil moisture values are depicted by colored circles with a diameter corresponding to the real GPR antenna footprint. The coverage rate of the GPR acquisition was estimated at around $9 \%$ of the field area for this configuration of acquisition, assuming an antenna footprint of $2 \mathrm{~m}^{2}$. Soil moisture data acquired for the first three dates
HESSD

$10,4063-4097,2013$

\section{Temporal stability of soil moisture \\ patterns \\ J. Minet et al.}

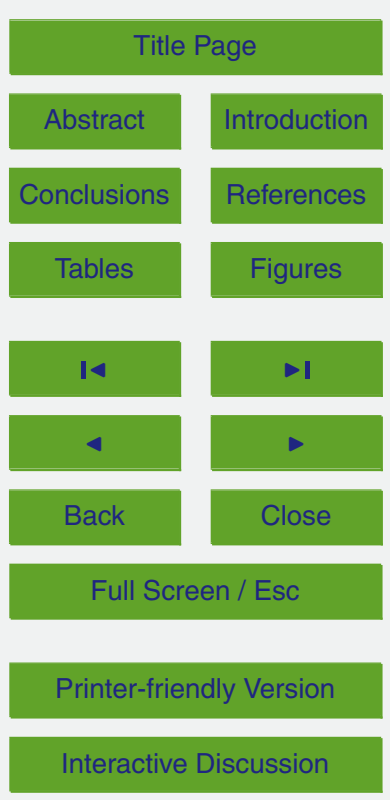


showed similar patterns and drier conditions than the last two ones (see Table 2), which was related to the recorded precipitation (see Fig. 2). The overall agreement between the soil moisture maps in terms of soil moisture patterns and its evolution according to meteorological events gave valuable confidence in the GPR method for soil moisture 5 mapping.

The variograms were similar for the first three dates, with respect to nugget and sill variances and ranges (Table 2). The soil moisture patterns from the first three dates showed stationarity within the field extent, with a range around $75 \mathrm{~m}$. The last two dates, characterized by wetter conditions, showed different soil moisture patterns with a sharp - amplification in nugget and sill variances, in correspondence to what is observed in Western et al. (1998) in wet conditions. The relatively large nugget effects that were observed can be attributed to three causes (Chiles and Delfiner, 1999), namely, (1) measurement and positioning errors, (2) unrevealed spatial variability at the resolution scale and (3) small-scale spatial variability within the support scale. Herein, nugget effects may be mainly attributed to the unrevealed spatial variability within the support scale. Indeed, along the acquisition lines, the spacing $(2 \mathrm{~m})$ was close to the support scale (1.5 $\mathrm{m}$ in diameter), which excluded that unrevealed variability between the support and spacing scales may solely explain the large nugget effects. The measurement error in soil moisture using the same GPR technique was evaluated in the same field in Minet et al. (2012) using three repetitions of the acquisition within three hours and the repetition error was evaluated as $0.0169 \mathrm{~m}^{3} \mathrm{~m}^{-3}$, which is far below the observed nugget effects.

Soil moisture spatial variability was maximal in wetter conditions because of the presence of both nearly saturated and relatively dry areas. This can be attributed to shallow characterization depth of the GPR method with respect to the rapid drainage of the shallow soil layer for some locations. Although soil moisture variability is generally expected to decrease with wet conditions (Famiglietti et al., 2008), De Lannoy et al. (2006) already remarked that this decreasing trend in soil moisture variability with
HESSD

10, 4063-4097, 2013

Temporal stability of soil moisture

patterns

J. Minet et al.

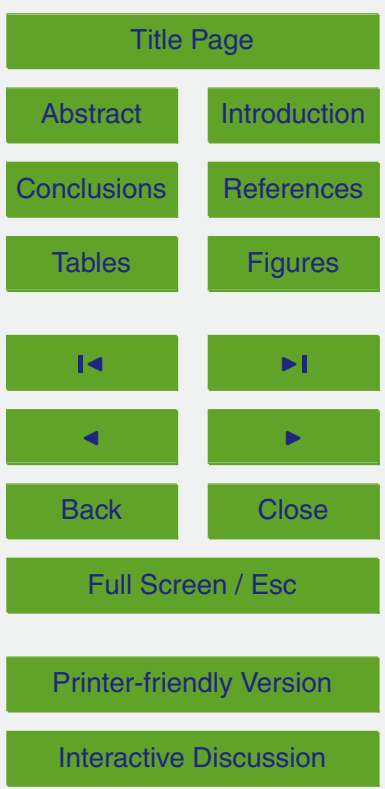


high soil moisture was not observed for shallow $(0-10 \mathrm{~cm})$ soil layer but only for deeper layers, because of the faster soil moisture dynamics of the shallow layer.

\subsection{Line effect}

The uneven acquisition sampling resulted in stripped soil moisture patterns (see Fig. 4), 5 i.e. denoting a line effect, which could be observed by a larger spatial coherency of the soil moisture values when looking along the acquisition compared to the perpendicular direction to the acquisition lines. We could interestingly notice that this line effect was observed at same locations for repeated dates (Fig. 4), i.e. it seemed related to local soil conditions and not to a sensor drift. The line effect was higher for the last two dates in the wettest conditions.

This line effect was already observed and discussed in Minet et al. (2011) in another field using the same mobile platform. It was mainly attributed to the soil compaction induced by the ploughing or fertilizer spreading machine, as we followed the same direction with the platform. The largest line effect that was observed here with wet 5 conditions may be related to: (1) the overall largest soil moisture variance observed in wet conditions or to (2) a real increase in the stripped soil moisture patterns due to the repeated passes of the ATV holding the GPR system. It was observed in situ that the passes of the ATV slightly compacted the soil and this might have affected the volumetric soil moisture. In addition, flow paths may have been deviated by these 20 acquisition lines, particularly in flat areas. The rectangular neighboring window used in the soil moisture interpolation permitted to deal with this line effect for producing the soil moisture maps without influence of the acquisition lines.

\subsection{Comparison with soil core sampling measurements}

Figure 5 presents the comparison between interpolated GPR-derived soil dielectric permittivity $\varepsilon_{\mathrm{GPR}}$ and volumetric soil moisture $\theta_{\mathrm{V}}$ from the soil sampling measurements. The standard relationship of Topp et al. (1980) that was used for translating the GPR

\section{HESSD}

10, 4063-4097, 2013
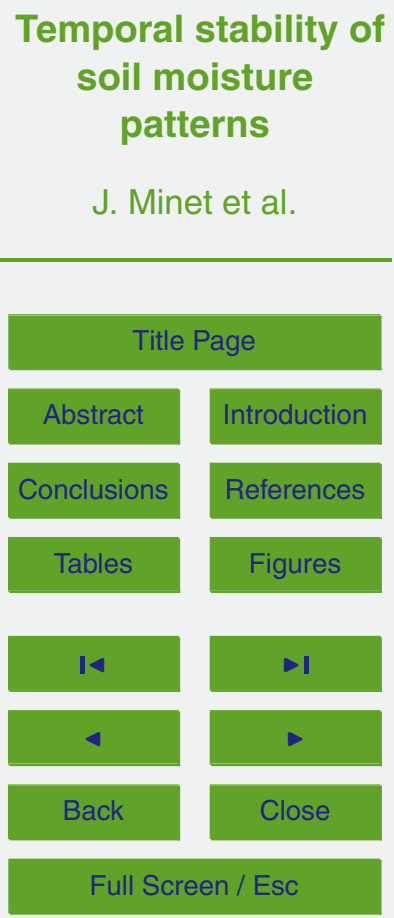

Printer-friendly Version

Interactive Discussion 
derived dielectric permittivities into soil moisture values was drawn for comparison. There was an overall moderate agreement between the soil permittivity and volumetric moisture with an RMSE $E_{\text {Topp }}$ of $0.0519 \mathrm{~m}^{3} \mathrm{~m}^{-3}$. There were poorer agreements for the last two dates, with a small sensitivity of volumetric soil moisture to the large range of 5 GPR-derived dielectric permittivity. The observed discrepancies could be attributed to the different support scales and characterization depths of the techniques, with respect to the small-scale variability of soil moisture. In particular, the small sensitivity of the ground-sampled soil moisture values to the large variation of the dielectric permittivity for the last two dates may be related to the shallower characterization depth for the 10 GPR compared to the ground samples, with respect to the larger dynamics of the upper soil layers. Nevertheless, as point soil moisture were compared with interpolated dielectric permittivity values, the range of the discrepancies could be simply related to the interpolation uncertainties (Minet et al., 2012), at least for the first three dates.

\section{Temporal stability of soil moisture patterns}

\subsection{Relative difference to field-average}

Figure 6 presents the maps of the time-averaged indicator based on the relative difference of soil moisture to the field-average. The locations where $\bar{\delta}_{i}=0$ (Fig. 6a) gave on average over time the field-average. Persistently drier $\left(\bar{\delta}_{i}<0\right)$ and wetter $\left(\bar{\delta}_{i}>0\right)$ areas are depicted in orange and blue, respectively, and divide the field in almost equal parts. The time-averaged soil moisture difference patterns could be related to topographic features in some part of the field. For instance, the largest persistently wet areas were located in flat areas, in both the most and less elevated places of the field.

The second map (Fig. 6b) indicates the standard deviation over time of the difference of soil moisture to the field-average. The locations where $\sigma\left(\delta_{i}\right)$ was low indicated

a high time-stability of soil moisture with respect to the field-average. The $\sigma\left(\delta_{i}\right)$ pattern appeared less spatially correlated than the $\bar{\delta}_{i}$ pattern. The third map $\left(\mathrm{TSI}_{\delta_{j}}\right)$ (Fig. 6c)

HESSD

10, 4063-4097, 2013
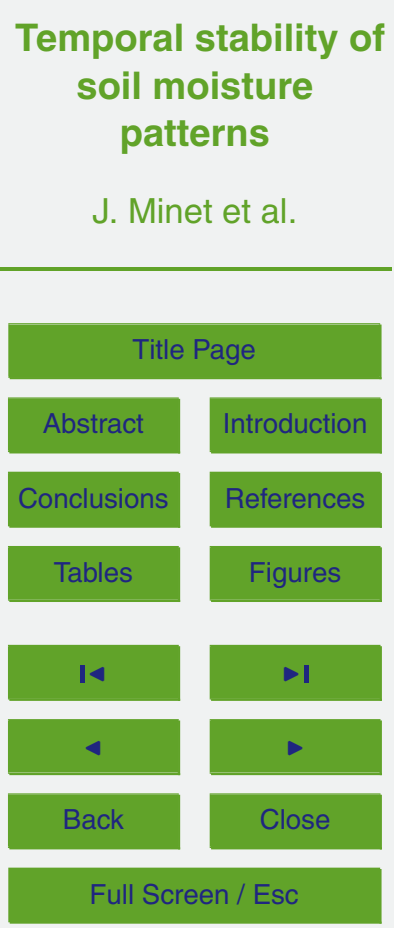

Printer-friendly Version

Interactive Discussion 
combined the information of the first two maps and gave an assessment of the temporal stability of the field-average soil moisture.

The distributions of the mean and the standard deviation of the relative difference $\left(\bar{\delta}_{i}\right.$ and $\left.\sigma\left(\delta_{i}\right)\right)$ computed for each interpolated points are presented in Fig. 7. The mean of 5 the relative difference ranges from -0.40 to $0.33 \mathrm{~m}^{3} \mathrm{~m}^{-3}$ while the standard deviation ranges from 0 to $0.27 \mathrm{~m}^{3} \mathrm{~m}^{-3}$. Although no clear trend could be drawn from the relationship between these two variables, it could be noticed that the largest $\sigma\left(\delta_{i}\right)$ values were encountered for slightly positive $\bar{\delta}_{i}$, meaning that moderately wet locations were the less time-stable. This was related to some saturated areas $(\theta \approx 0.5)$ observed in the last two dates but not always in the first three dates.

\subsection{Intersection of field-average soil moisture areas}

Figure 8 shows the areas giving the field-average soil moisture for the five dates with a tolerance of $\pm 0.02 \mathrm{~m}^{3} \mathrm{~m}^{-3}$ and their intersection between the five dates (second method). There was a remarkable temporal stability of soil moisture patterns for the 15 sets of the first three and the last two dates, respectively, i.e. the zones outlined by black lines are similar for these two sets of dates. However, due to moderate precipitation ( $24.8 \mathrm{~mm}$ between 24 and 30 March 2010), the soil moisture pattern greatly changed for the last two dates. The zones indicating the field-average soil moisture shrank from dry to wet conditions as a result of the increase in soil moisture variance with wet conditions. There existed locations that indicated the field-average for all the five dates (red lines), but these locations were split and dispersed within the field.

\subsection{Temporal stability of soil moisture from soil core sampling measurements}

The same analysis on the temporal stability using the relative difference method was performed with soil core sampling measurements and results are depicted in Fig. 9. The mean of the relative difference was ranging from -0.12 to $0.19 \mathrm{~m}^{3} \mathrm{~m}^{-3}$ while the standard deviation was ranging from 0.11 to $0.29 \mathrm{~m}^{3} \mathrm{~m}^{-3}$, which was smaller than the

HESSD

10, 4063-4097, 2013

Temporal stability of soil moisture

patterns

J. Minet et al.

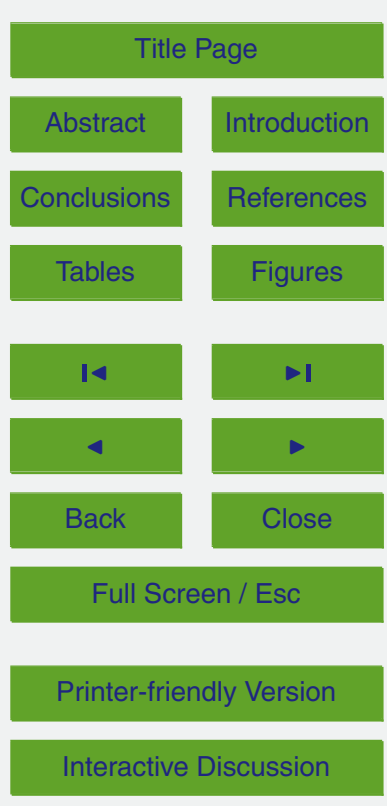

Interactive Discussion 
relative difference from the interpolated GPR-derived soil moisture maps. Four sampling points appeared to fall into the area showing the intersection of time-stable locations (second method) and they were outlined with larger error bars for $\sigma(\delta)_{i}$ in Fig. 9. Three of these points showed a large temporal stability for the volumetric soil moisture 5 data from soil core sampling as well, as they actually correspond to the three smallest $\mathrm{TSI}_{\delta_{i}}$. Locations showing temporal stability of field-average soil moisture could thus be also detected using the soil core sampling measurements.

\subsection{Comparison of the two methods}

Locations showing a temporal stability of field-average soil moisture were revealed in 10

the soil moisture patterns. There were good matches between the lowest $\left|\bar{\delta}_{i}\right|$ and $\mathrm{TSI}_{\delta_{i}}$ values and the time-stable zones outlined by the second method.

The proportions of the field surface that showed the field-average were however different between the two methods, as shown in the Table 3. Considering all acquisitions,

$1510.1 \%$ of locations where $\left|\bar{\delta}_{i}\right|<0.02 \mathrm{~m}^{3} \mathrm{~m}^{-3}$ (first method) could be identified whereas the intersection of the area showing the field-average $\pm 0.02 \mathrm{~m}^{3} \mathrm{~m}^{-3}$ (second method) concerned only $5.0 \%$ of the field area. However, when fewer sets of acquisitions are considered, the intersection method delineated larger areas compared to the indicator $\left|\bar{\delta}_{i}\right|$ method, reaching $21.3 \%$ (second method) against $11.0 \%$ (first method) of the field 20 surface when considering only the first three acquisitions. As we surveyed the field in a rather short time range (i.e. 22 days), the second method still resulted in intersected areas indicating the field-average between all acquisitions, but over longer period, the second method may fail to identify time-stable areas because of the absence of intersection. Therefore, the second method based on the intersection of time-stable areas 25 is suited only when a few acquisitions are considered (low temporal sampling). On the other hand, it is better adapted for data with a continuous spatial coverage than the first method.
HESSD

10, 4063-4097, 2013

Temporal stability of soil moisture

patterns

J. Minet et al.

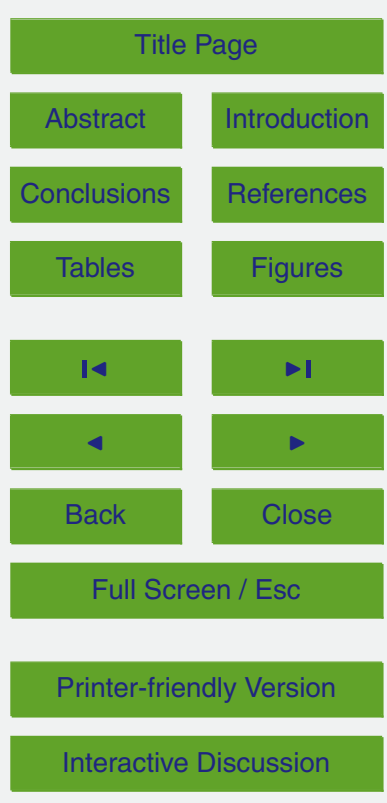

Interactive Discussion 


\subsection{Comparison with previous studies}

Compared to previous studies where they were used, the relative difference indicators $\bar{\delta}_{i}$ and $\sigma\left(\delta_{i}\right)$ showed a great temporal stability of field-average soil moisture. The most comprehensive review about temporal stability of soil moisture was given by 5 Brocca et al. (2009, Table 1). Few studies resulted in smaller ranges in terms of $\bar{\delta}_{i}$ and $\sigma(\delta)_{i}$ than the ones observed in this study (i.e. $\bar{\delta}_{i}=-0.40$ to 0.33 and $\sigma(\delta)_{i}=0$ to $\left.0.08 \mathrm{~m}^{3} \mathrm{~m}^{-3}\right)$. In Jacobs et al. (2004), rather large criteria for highlighting time-stable locations of the field-average were used, that were, time-stable locations were defined by $\left|\delta_{i}\right|<0.05$ or $0.10 \mathrm{~m}^{3} \mathrm{~m}^{-3}$ and covered $13-18 \%$ and $27-37 \%$ of fields areas, re10 spectively. Applying the same thresholds, time-stable locations could be identified in, respectively, $24 \%$ and $46 \%$ of the field area in our study. This high temporal stability was attributed to the short time range and the small number of acquisition of the GPR field acquisitions, although, for instance, a shorter time range (14 days) was used in Jacobs et al. (2004). A large part of this high temporal stability could be also attributed to the interpolation of point-measurements that have smoothed local point-measurements discrepancies. The interpolation approximately led to a half-reduction in the standard deviation of soil moisture (see Table 2).

The time-stable zones indicating the field-average appeared to be located inbetween low and high elevated areas, as already noticed in many previous studies (Brocca et al., 2009; Jacobs et al., 2004; Mohanty and Skaggs, 2001). Unfortunately, high-resolution soil information was lacking to relate the spatiotemporal pattern to soil conditions.

Lastly, the use of a proximal soil mapping tool like the GPR allows to get an unprecedented soil moisture spatial resolution and to use the intersection of time-stable areas as a method for revealing locations showing the field-average. Given the observed spatial coherence of the soil moisture patterns, determining time-stable areas rather than time-stable points was less uncertain given the high number of spatially-coherent data acquired with the GPR method. Therefore, this method gives more confidence for the
HESSD

$10,4063-4097,2013$
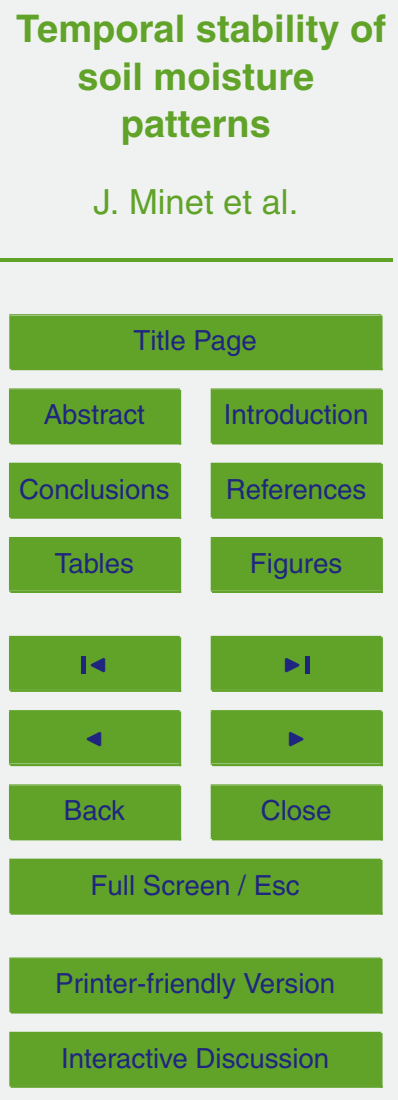
choice of locations where sensors could be installed, as eventually time-stable areas can be identified rather than time-stable points.

\section{Conclusions and perspectives}

Soil moisture patterns were measured by a proximal GPR mobile platform in a 2.5 ha 5 agricultural field at five dates in spring 2010. Time-lapse measurements at high spatial resolution permitted to extensively study the spatiotemporal soil moisture variability and to investigate the temporal stability of soil moisture.

The evolution of the soil moisture patterns was mainly governed by rainfall, i.e. similar patterns were obtained for the different dates unless large rainfall occurred. The over10 all good time stability of the soil moisture patterns further validated this GPR method for soil moisture mapping. Soil moisture from soil core sampling were in a moderate agreement with GPR-derived estimates $\left(\mathrm{RMSE}_{\mathrm{fit}}=0.0475 \mathrm{~m}^{3} \mathrm{~m}^{-3}\right)$ and the discrepancies were mainly related to the shallow characterization depth of the GPR compared to the soil core sampling and to interpolation uncertainties.

15 Temporal stability of the field-average soil moisture was revealed by two methods, that were: (1) the computation of the mean and standard deviation over time of the relative difference of soil moisture to the field-average, as defined by Vachaud et al. (1985) and by (2) the intersection of areas showing the field-average. These methods were in accordance, although they showed different degrees of temporal stability extents depending on the number of acquisitions that were taken into account. Considering the five acquisitions, locations where the mean relative difference $\left|\bar{\delta}_{i}\right|$ was below $0.02 \mathrm{~m}^{3} \mathrm{~m}^{-3}$ extended up to $10 \%$ of the field area, whereas the intersection of areas showing the field-average within a tolerance of $0.02 \mathrm{~m}^{3} \mathrm{~m}^{-3}$ covered $5 \%$ of the field area. Considering a fewer sets of acquisitions, the second method however delineated larger areas than the first method. Compared to previous studies, the temporal stability of the field-average soil moisture was high, with $24 \%$ of locations showing $\left|\bar{\delta}_{i}\right|<0.05 \mathrm{~m}^{3} \mathrm{~m}^{-3}$, although it was attributed to the relatively small time frame over 4080

\section{HESSD}

10, 4063-4097, 2013

Temporal stability of soil moisture

patterns

J. Minet et al.

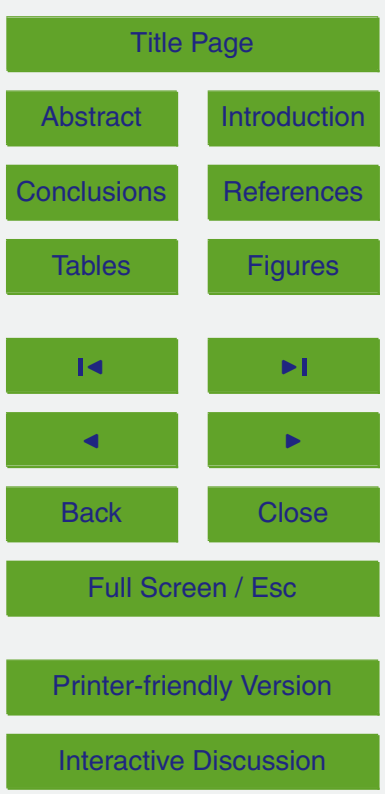


which the field campaigns were performed and to the interpolation step that smoothed extremes values. Soil moisture data from the soil core sampling also exhibited temporal stability of the field-average and some sampling locations were found to be in accordance with the intersected time-stable areas determined using GPR-derived soil 5 moisture data.

To the best of our knowledge, among the large body of literature about the temporal stability of soil moisture, there were no studies using soil moisture estimates from proximal sensing platform such as GPR. The use of the GPR platform permitted to investigate the temporal stability pattern using a large number of measurements at an 10 unprecedented spatial resolution at the field scale. Owing to the proximity of its support scale to its spacing, the technique was able to nearly acquire the continuous soil moisture patterns and provided coherent interpolated maps. The main output of this GPR method regarding temporal stability studies is that time-stable areas and spatial patterns could be revealed rather than time-stable points. Time-stable areas are more informative given their spatial coherence and the understanding of the associated spatial pattern. This study showed the potential of the proposed GPR method for the determination of the best time-stable locations for in situ sensors and to model complete soil moisture patterns in data assimilation frameworks. These promising results should be nevertheless corroborated by conducting field acquisitions over a larger time frame, e.g. over a year, and for different field topographies and surface conditions.

Acknowledgements. The research presented in this paper was funded by the Belgian Science Policy Office in the frame of the Stereo II programme - project SR/00/100 (HYDRASENS) and the DIGISOIL project financed by the European Commission under the 7th Framework Programme for Research and Technological Development, Area "Environment", Activity 6.3 25 "Environmental Technologies".
HESSD

$10,4063-4097,2013$
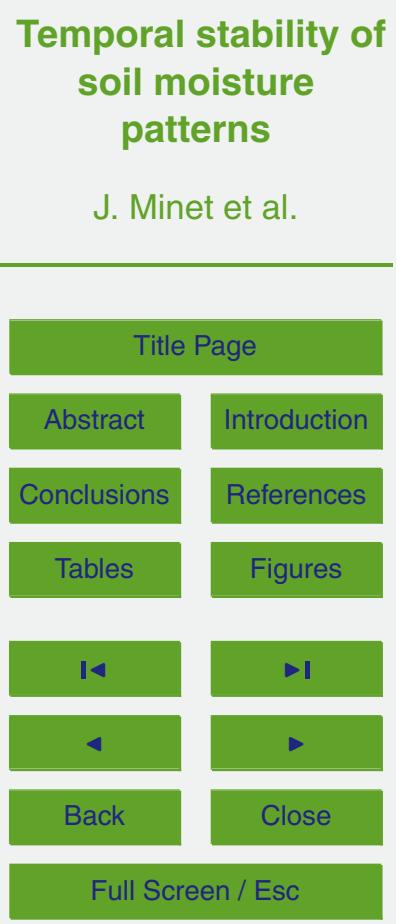

Printer-friendly Version

Interactive Discussion 


\section{References}

Beven, K. J. and Kirkby, M. J.: A physically based, variable contributing area model of basin hydrology, Hydrolog. Sci. Bull., 24, 43-69, 1979. 4066

Blöschl, G. and Sivapalan, M.: Scale issues in hydrological modeling - a review, Hydrol. Process., 9, 251-290, 1995. 4067

Brocca, L., Melone, F., Moramarco, T., and Morbidelli, R.: Soil moisture temporal stability over experimental areas in Central Italy, Geoderma, 148, 364-374, doi:10.1016/j.geoderma.2008.11.004, 2009. 4065, 4066, 4071, 4079

Chiles, J.-P. and Delfiner, P.: Geostatistics - Modeling Spatial Uncertainty, Wiley Series in Probability and Statistics, Hoboken, USA, 1999. 4074

Cosh, M. H., Jackson, T. J., Bindlish, R., and Prueger, J. H.: Watershed scale temporal and spatial stability of soil moisture and its role in validating satellite estimates, Remote Sens. Environ., 92, 427-435, doi:10.1016/j.rse.2004.02.016, 2004. 4065

Crow, W. T. and Ryu, D.: A new data assimilation approach for improving runoff prediction using remotely-sensed soil moisture retrievals, Hydrol. Earth Syst. Sci., 13, 1-16, doi:10.5194/hess-13-1-2009, 2009. 4064

da Silva, A. P., Nadler, A., and Kay, B. D.: Factors contributing to temporal stability in spatial patterns of water content in the tillage zone, Soil Till. Res., 58, 207-218, 2001. 4065, 4066

De Lannoy, G. J., Verhoest, N. E., Houser, P. R., Gish, T. J., and Van Meirvenne, M.: Spatial and temporal characteristics of soil moisture in an intensively monitored agricultural field (OPE3), J. Hydrol., 331, 719-730, 2006. 4074

De Lannoy, G. J. M., Reichle, R. H., Houser, P. R., Pauwels, V. R. N., and Verhoest, N. E. C.: Correcting for forecast bias in soil moisture assimilation with the ensemble Kalman filter, Water Resour. Res., 43, W09410, doi:10.1029/2006WR005449, 2007. 4064

Famiglietti, J. S., Ryu, D., Berg, A. A., Rodell, M., and Jackson, T. J.: Field observations of soil moisture variability across scales, Water Resour. Res., 44, W01423, doi:10.1029/2006WR005804, 2008. 4074

Grayson, R. B. and Western, A. W.: Towards areal estimation of soil water content from point measurements: time and space stability of mean response, J. Hydrol., 207, 68-82, 1998. 4065, 4066
HESSD

$10,4063-4097,2013$

Temporal stability of soil moisture

patterns

J. Minet et al.

Title Page

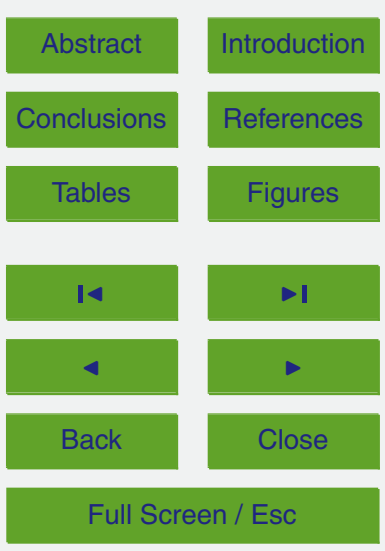

Printer-friendly Version

Interactive Discussion 
Grayson, R. B., Western, A. W., Chiew, F. H. S., and Blöschl, G.: Preferred states in spatial soil moisture patterns: local and nonlocal controls, Water Resour. Res., 33, 2897-2908, 1997. 4066

Guber, A. K., Gish, T. J., Pachepsky, Y. A., Van Genuchten, M. T., Daughtry, C. S. T., Nicholson, T. J., and Cady, R. E.: Temporal stability in soil water content patterns across agricultural fields, Catena, 73, 125-133, 2008. 4065

Güntner, A., Seibert, J., and Uhlenbrook, S.: Modeling spatial patterns of saturated areas: an evaluation of different terrain indices, Water Resour. Res., 40, W05114, doi:10.1029/2003WR002864, 2004. 4066

10 Hawley, M. E., Jackson, T. J., and McCuen, R. H.: Surface soil-moisture variation on small agricultural watersheds, J. Hydrol., 62, 179-200, 1983. 4066

Heathman, G. C., Cosh, M. H., Merwade, V., and Han, E.: Multi-scale temporal stability analysis of surface and subsurface soil moisture within the Upper Cedar Creek Watershed, Indiana, Catena, 95, 91-103, doi:10.1016/j.catena.2012.03.008, 2012. 4065

$15 \mathrm{Hu}$, W., Shao, M., Han, F., Reichardt, K., and Tan, J.: Watershed scale temporal stability of soil water content, Geoderma, 158, 181-198, doi:10.1016/j.geoderma.2010.04.030, 2010. 4071

Hupet, F. and Vanclooster, M.: Intraseasonal dynamics of soil moisture variability within a small agricultural maize cropped field, J. Hydrol., 261, 86-101, 2002. 4066

Jacobs, J. M., Mohanty, B. P., Hsu, E. C., and Miller, D.: SMEX02: Field scale variability, time stability and similarity of soil moisture, Remote Sens. Environ., 92, 436-446, doi:10.1016/j.rse.2004.02.017, 2004. 4065, 4066, 4067, 4071, 4072, 4079

Jadoon, K. Z., Lambot, S., Scharnagl, B., van der Kruk, J., Slob, E., and Vereecken, H.: Quantifying field-scale surface soil water content from proximal GPR signal inversion in the time domain, Near Surf. Geophys., 8, 483-491, doi:10.3997/1873-0604.2010036, 2010. 4068

Jonard, F., Weihermüller, L., Jadoon, K., Schwank, M., Vereecken, H., and Lambot, S.: Mapping field-scale soil moisture with L-band radiometer and ground-penetrating radar over bare soil, IEEE T. Geosci. Remote, 49, 2863-2875, doi:10.1109/TGRS.2011.2114890, 2011. 4068

Lambot, S., Slob, E. C., van den Bosch, I., Stockbroeckx, B., and Vanclooster, M.: Modeling of ground-penetrating radar for accurate characterization of subsurface electric properties,

30 IEEE T. Geosci. Remote, 42, 2555-2568, 2004. 4067, 4069

Lambot, S., Weihermüller, L., Huisman, J. A., Vereecken, H., Vanclooster, M., and Slob, E. C.: Analysis of air-launched ground-penetrating radar techniques to measure the soil surface
HESSD

10, 4063-4097, 2013
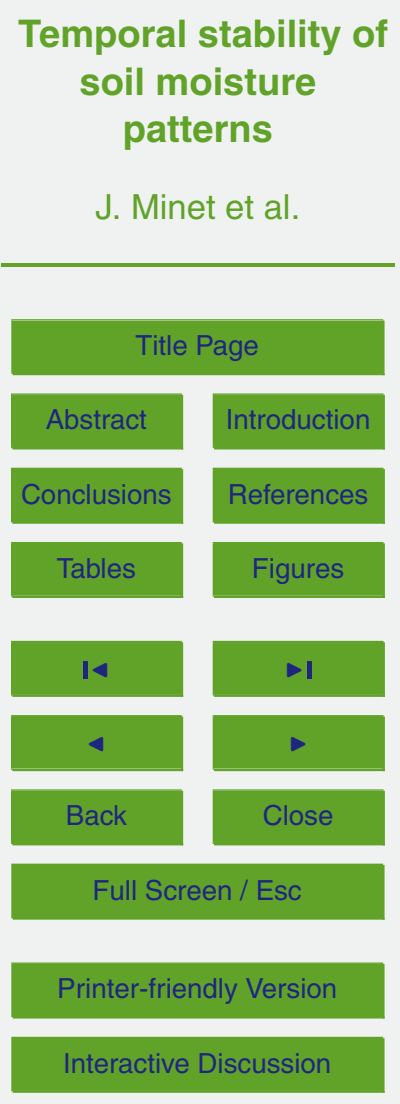
water content, Water Resour. Res., 42, W11403, doi:10.1029/2006WR005097, 2006. 4067, 4069

Lambot, S., Slob, E. C., Chavarro, D., Lubczynski, M., and Vereecken, H.: Measuring soil surface water content in irrigated areas of southern Tunisia using full-waveform inversion of

5 proximal GPR data, Near Surf. Geophys., 6, 403-410, 2008. 4068

Loew, A. and Mauser, W.: On the disaggregation of passive microwave soil moisture data using a priori knowledge of temporally persistent soil moisture fields, IEEE T. Geosci. Remote, 46, 819-834, doi:10.1109/TGRS.2007.914800, 2008. 4065

Minet, J., Wahyudi, A., Bogaert, P., Vanclooster, M., and Lambot, S.: Mapping shallow soil moisture profiles at the field scale using full-waveform inversion of ground penetrating radar data, Geoderma, 161, 225-237, doi:10.1016/j.geoderma.2010.12.023, 2011. 4068, 4075

Minet, J., Bogaert, P., Vanclooster, M., and Lambot, S.: Validation of ground penetrating radar full-waveform inversion for field scale soil moisture mapping, J. Hydrol., 424-425, 112-123, doi:10.1016/j.jhydrol.2011.12.034, 2012. 4068, 4069, 4070, 4073, 4074, 4076

Mittelbach, H. and Seneviratne, S. I.: A new perspective on the spatio-temporal variability of soil moisture: temporal dynamics versus time-invariant contributions, Hydrol. Earth Syst. Sci., 16, 2169-2179, doi:10.5194/hess-16-2169-2012, 2012. 4066

Mohanty, B. P. and Skaggs, T. H.: Spatio-temporal evolution and time-stable characteristics of soil moisture within remote sensing footprints with varying soil, slope, and vegetation, Adv.

$20 \quad$ Water Resour., 24, 1051-1067, 2001. 4065, 4066, 4067, 4071, 4079

Pauwels, V. R. N., Hoeben, R., Verhoest, N. E. C., De Troch, F. P., and Troch, P. A.: Improvement of TOPLATS-based discharge predictions through assimilation of ERS-based remotely sensed soil moisture values, Hydrol. Process., 16, 995-1013, doi:10.1002/hyp.315, 2002. 4064

Quinn, P. F., Beven, K. J., and Lamb, R.: The $\ln (A / \tan$-beta) index - how to calculate it and how to use it within the TOPMODEL framework, Hydrol. Process., 9, 161-182, 1995. 4066

Seneviratne, S. I., Corti, T., Davin, E. L., Hirschi, M., Jaeger, E. B., Lehner, I., Orlowsky, B., and Teuling, A. J.: Investigating soil moisture-climate interactions in a changing climate: a review, Earth-Sci. Rev., 99, 125-161, 2010. 4064

30 Starks, P. J., Heathman, G. C., Jackson, T. J., and Cosh, M. H.: Temporal stability of soil moisture profile, J. Hydrol., 324, 400-411, doi:10.1016/j.jhydrol.2005.09.024, 2006. 4065 
Topp, G. C., Davis, J. L., and Annan, A. P.: Electromagnetic determination of soil water content: measurements in coaxial transmission lines, Water Resour. Res., 16, 574-582, 1980. 4069, 4075

Vachaud, G., Passerat de Silans, A., Balabanis, P., and Vauclin, M.: Temporal stability of spa5 tially measured soil-water probability density function, Soil Sci. Soc. Am. J., 49, 822-828, 1985. 4065, 4068, 4071, 4080

Van Orshoven, J. and Vandenbroucke, D.: Guide de l'utilisateur d'AARDEWERK, base de données pédologiques, Tech. rep., Institute for land and water management, K. U. Leuven, Leuven, Belgium., 1993. 4068

10 Vernieuwe, H., De Baets, B., Minet, J., Pauwels, V. R. N., Lambot, S., Vanclooster, M., and Verhoest, N. E. C.: Integrating coarse-scale uncertain soil moisture data into a fine-scale hydrological modelling scenario, Hydrol. Earth Syst. Sci., 15, 3101-3114, doi:10.5194/hess15-3101-2011, 2011. 4065

Western, A. W., Blöschl, G., and Grayson, R. B.: Geostatistical characterisation of soil moisture patterns in the Tarrawarra catchment, J. Hydrol., 205, 20-37, 1998. 4074

Western, A. W., Grayson, R. B., Blöschl, G., Willgoose, G. R., and McMahon, T. A.: Observed spatial organization of soil moisture and its relation to terrain indices, Water Resour. Res., 35, 797-810, 1999. 4066

Temporal stability of soil moisture

patterns

J. Minet et al.

Title Page

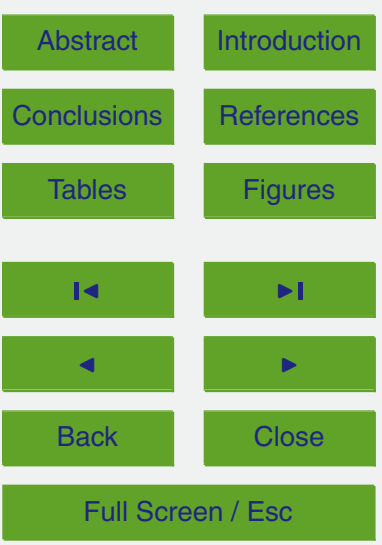

Printer-friendly Version

Interactive Discussion 


\section{HESSD}

10, 4063-4097, 2013

Temporal stability of soil moisture patterns

J. Minet et al.

Table 1. Presentation of the five GPR acquisitions.

\begin{tabular}{lccl}
\hline Date & $\begin{array}{c}\text { 10 days ant. } \\
\text { precipitation [mm] }\end{array}$ & $\begin{array}{c}\text { Number } \\
\text { of points }\end{array}$ & Duration \\
\hline 15 Mar 2010 & 6.3 & 1496 & $1 \mathrm{~h} 09^{\prime}$ \\
18 Mar 2010 & 0.1 & 1252 & $56^{\prime}$ \\
24 Mar 2010 & 5.1 & 1429 & $1 \mathrm{~h} \mathrm{01^{ \prime }}$ \\
30 Mar 2010 & 29.8 & 1227 & $1 \mathrm{~h} 32^{\prime}$ \\
6 Apr 2010 & 38.4 & 1759 & $51^{\prime}$ \\
\hline
\end{tabular}

Title Page

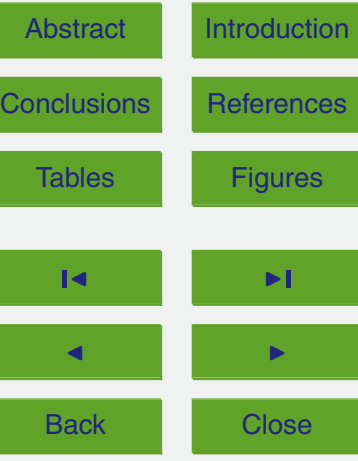

Full Screen / Esc

Printer-friendly Version

Interactive Discussion 


\section{HESSD}

10, 4063-4097, 2013

Temporal stability of soil moisture

patterns

J. Minet et al.

Table 2. Statistics of GPR-derived volumetric soil moisture expressed in $\left[\mathrm{m}^{3} \mathrm{~m}^{-3}\right]$ and variograms parameters (Nugget $\left[\mathrm{m}^{3} \mathrm{~m}^{-3}\right]^{2}$, Sill $\left[\mathrm{m}^{3} \mathrm{~m}^{-3}\right]^{2}$ and Range $[\mathrm{m}]$ ).

\begin{tabular}{|c|c|c|c|c|c|c|c|c|c|c|}
\hline \multirow[b]{2}{*}{ Date } & \multicolumn{3}{|c|}{ GPR measurements } & \multicolumn{6}{|c|}{ Interpolated soil moisture } & \multirow[b]{2}{*}{ Range } \\
\hline & Mean & Stdev & Skew & Mean & Stdev & Skew & Nugget & Sill & Nugget/Sill & \\
\hline 15 Mar 2010 & 0.228 & 0.067 & 0.512 & 0.227 & 0.042 & 0.307 & 0.0013 & 0.0041 & 32 & 79 \\
\hline 18 Mar 2010 & 0.235 & 0.062 & 0.367 & 0.233 & 0.032 & 0.218 & 0.0016 & 0.0034 & 47 & 77 \\
\hline $24 \operatorname{Mar} 2010$ & 0.240 & 0.064 & 0.281 & 0.239 & 0.035 & 0.059 & 0.0014 & 0.0036 & 39 & 70 \\
\hline 30 Mar 2010 & 0.295 & 0.114 & 0.214 & 0.292 & 0.052 & -0.007 & 0.0031 & 0.0115 & 26 & 107 \\
\hline 06 Apr 2010 & 0.298 & 0.115 & 0.076 & 0.297 & 0.057 & -0.007 & 0.0026 & 0.0113 & 23 & 109 \\
\hline
\end{tabular}

Title Page

Abstract

Introduction

Conclusions

References

Tables

Figures

14

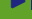

Back

Full Screen / Esc

Printer-friendly Version

Interactive Discussion 
Table 3. Proportions of the time-stable area showing the field-average at $\pm 0.02 \mathrm{~m}^{3} \mathrm{~m}^{-3}$ to the total surface.

\begin{tabular}{lcc}
\hline Acquisitions & First method & Second method \\
\hline All & $10.1 \%$ & $5.0 \%$ \\
First three & $11.0 \%$ & $21.3 \%$ \\
Last two & $7.1 \%$ & $16.1 \%$ \\
\hline
\end{tabular}

\section{HESSD}

10, 4063-4097, 2013

Temporal stability of soil moisture patterns

J. Minet et al.

Title Page

Abstract Introduction

Conclusions References

Tables

Figures

14

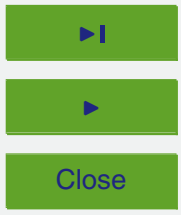

Back

Full Screen / Esc

Printer-friendly Version

Interactive Discussion 

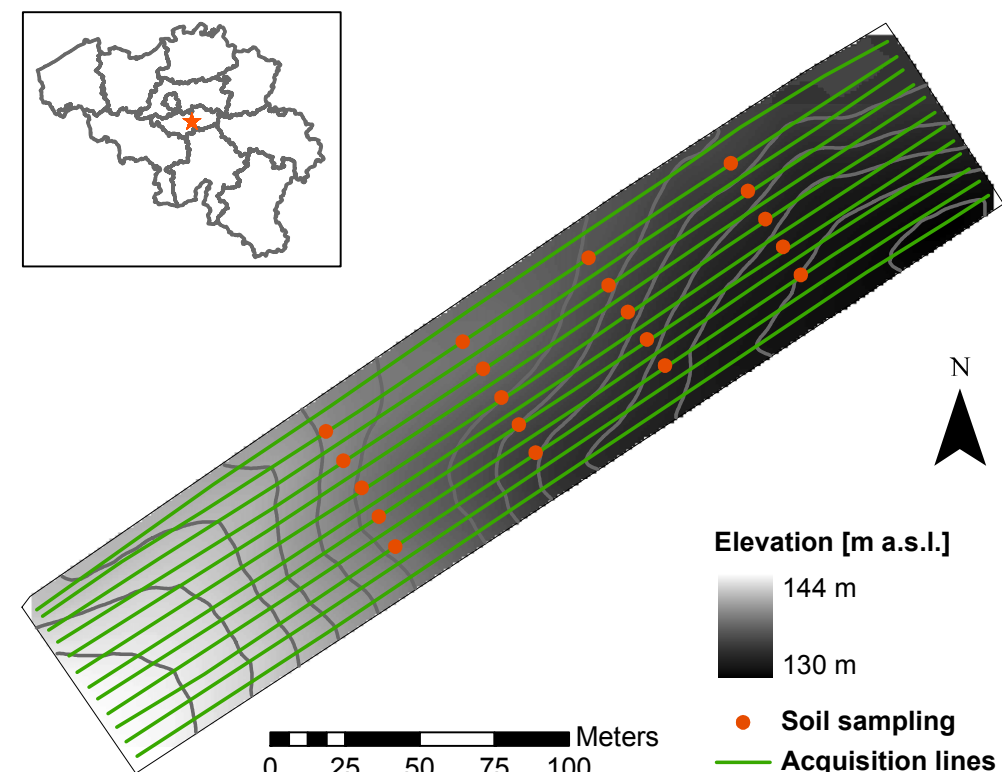

Elevation [m a.s.I.]

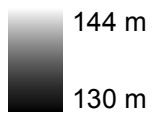

- Soil sampling

_ Acquisition lines

Fig. 1. Description of the study site. For each survey, GPR acquisition was performed along 12 parallel lines and volumetric soil sampling was performed in 20 locations.

\section{HESSD}

10, 4063-4097, 2013

Temporal stability of soil moisture patterns

J. Minet et al.

Title Page

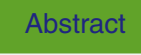

Introduction

Conclusions

References

Tables

Figures

14

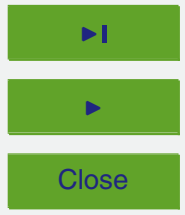

Back

Close

Full Screen / Esc

Printer-friendly Version

Interactive Discussion 


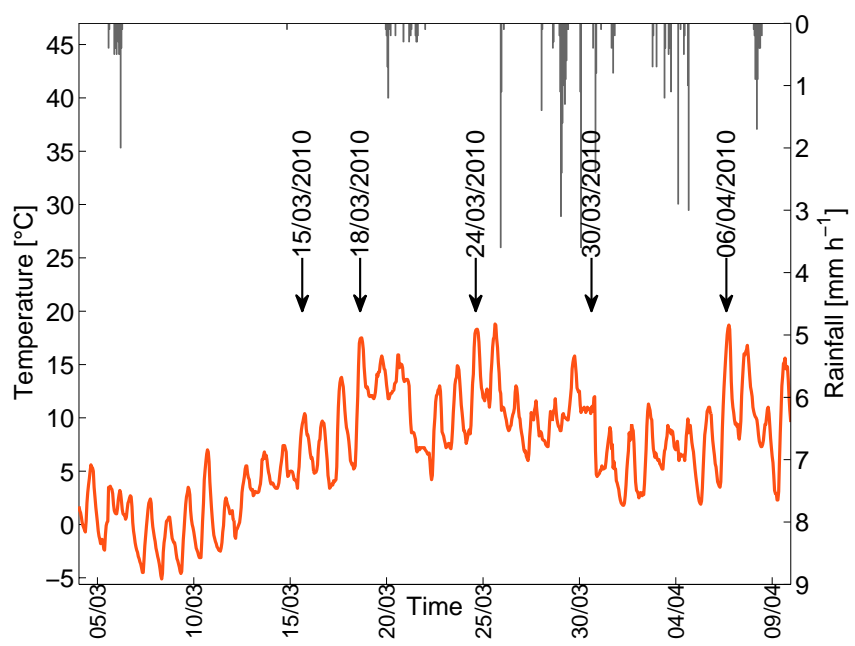

Fig. 2. Air temperature and precipitation depicted from 4 March to 10 April 2010. The dates of the GPR acquisitions are indicated with arrows.

\section{HESSD}

10, 4063-4097, 2013

Temporal stability of soil moisture patterns

J. Minet et al.

Title Page

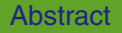

Introduction

Conclusions

References

Tables

Figures

14

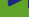

4

Back

Close

Full Screen / Esc

Printer-friendly Version

Interactive Discussion 


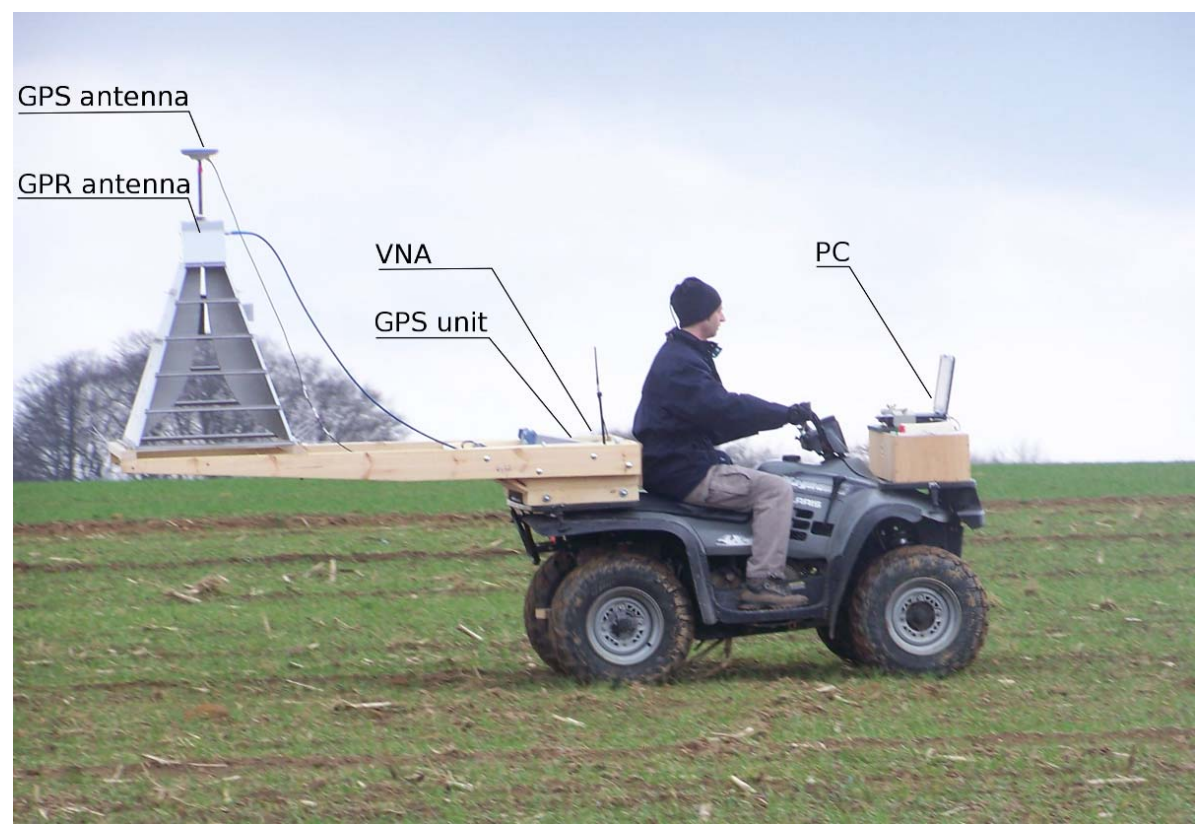

\section{HESSD}

10, 4063-4097, 2013

Temporal stability of soil moisture patterns

J. Minet et al.

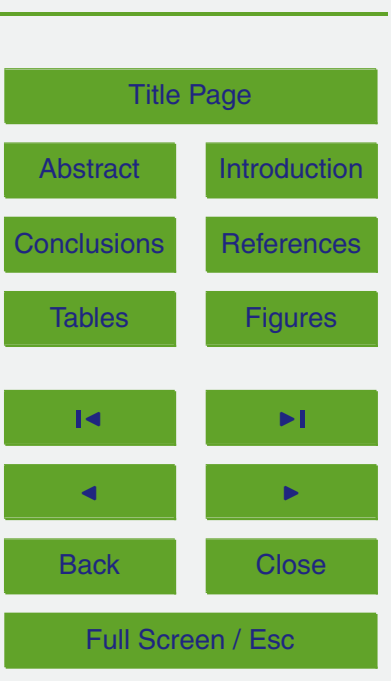

Fig. 3. All-terrain vehicle holding the GPR system constituted of the GPR horn antenna linked to a vector network analyzer (VNA), the GPS device, and the PC.

Printer-friendly Version

Interactive Discussion 


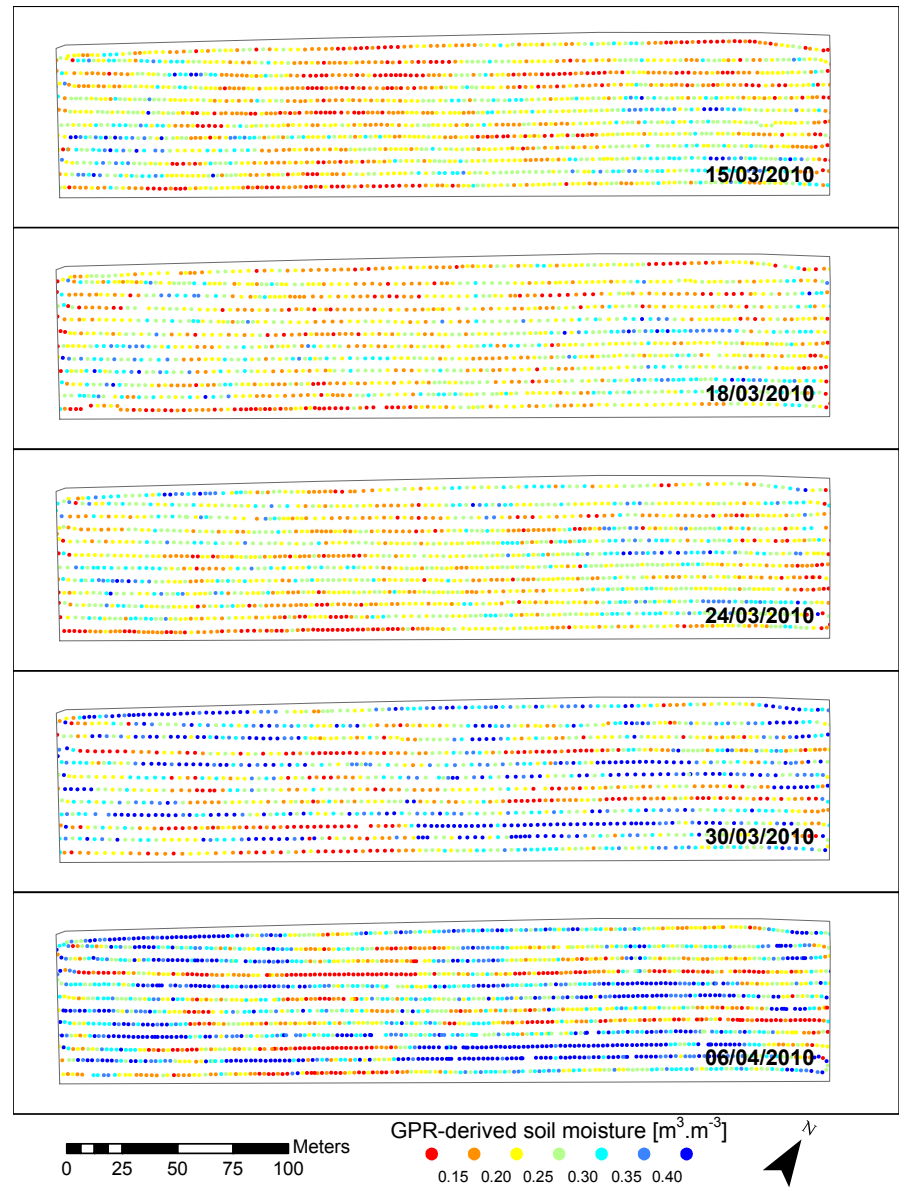

Fig. 4. GPR-derived soil moisture point-measurements depicted with the same color scale for the five GPR surveys.

\section{HESSD}

10, 4063-4097, 2013

Temporal stability of soil moisture patterns

J. Minet et al.

Title Page

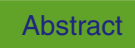

Introduction

Conclusions

References

Tables

Figures

14

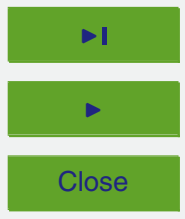

Back

Close

Full Screen / Esc

Printer-friendly Version

Interactive Discussion

cC) (i) 


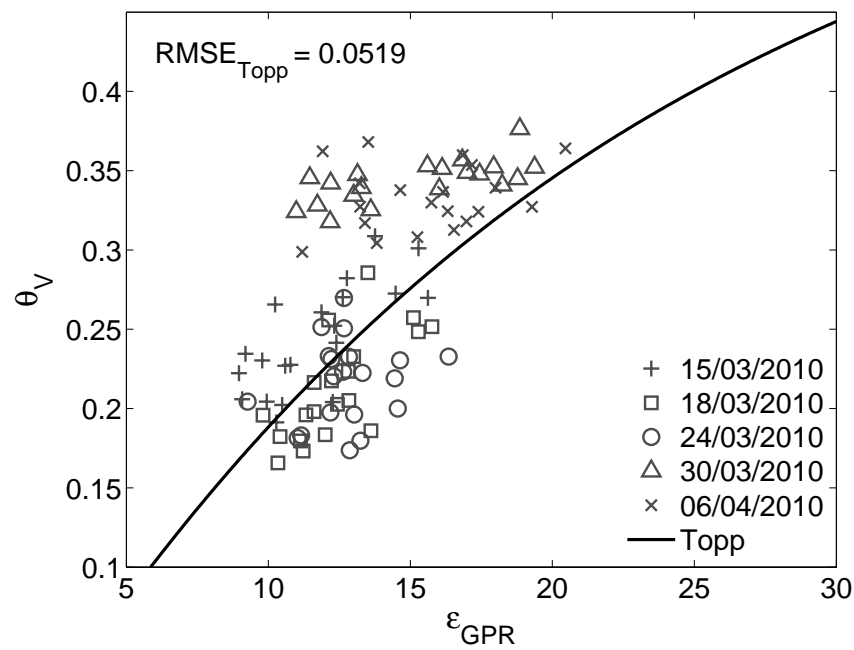

Fig. 5. Comparison between interpolated GPR-derived soil dielectric permittivity $\varepsilon_{\mathrm{GPR}}$ and volumetric sampling soil moisture $\theta_{\mathrm{V}}$ for all dates.

\section{HESSD}

10, 4063-4097, 2013

Temporal stability of soil moisture patterns

J. Minet et al.

Title Page

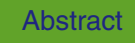

Introduction

Conclusions

References

Tables

Figures

14

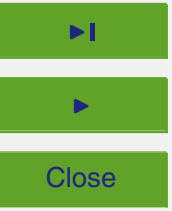

Back

Close

Full Screen / Esc

Printer-friendly Version

Interactive Discussion 


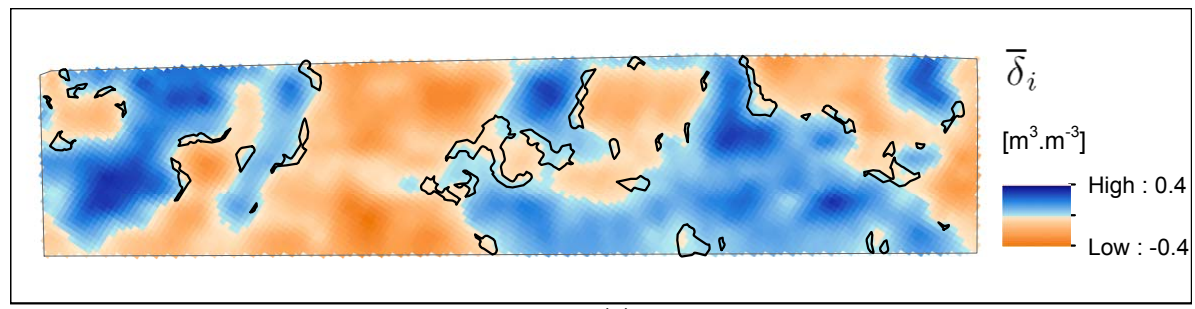

(a)

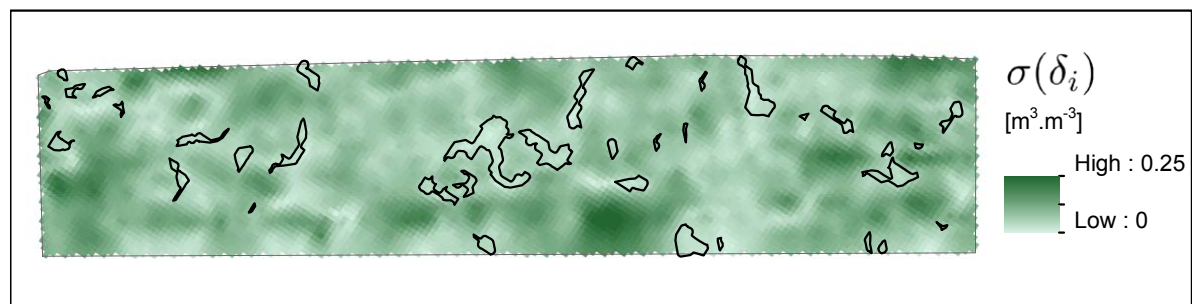

(b)

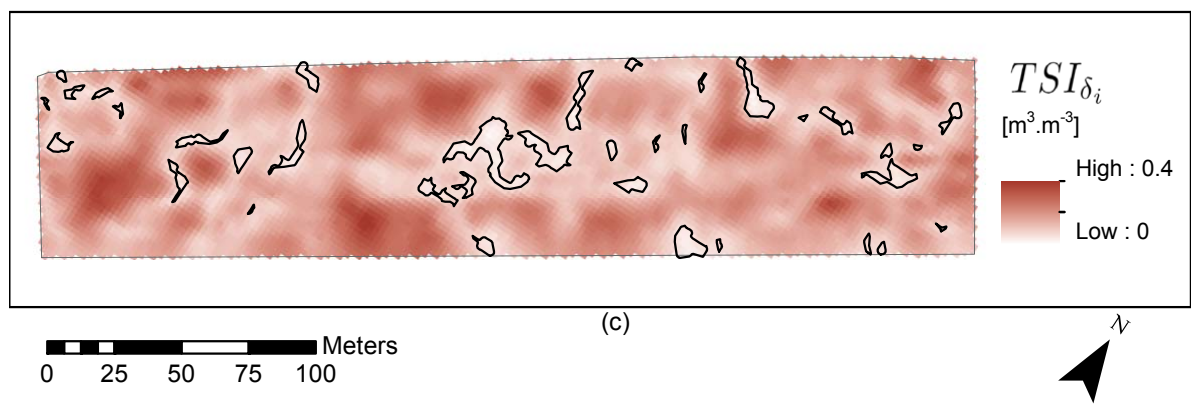

Fig. 6. Maps of the temporal stability computed by indicators based on the relative difference of soil moisture to the field-average (first method). From top to bottom, the mean of the relative difference $\bar{\delta}_{i}(\mathbf{a})$, the standard deviation of the relative difference $\sigma\left(\delta_{i}\right)$ (b) and the indicator $\mathrm{TSI}_{\delta,}$ (c) are presented. The time-stable zones determined by the second method are also outlined by black lines.

HESSD

10, 4063-4097, 2013

Temporal stability of soil moisture

patterns

J. Minet et al.

Title Page

Abstract

Introduction

Conclusions

References

Tables

Figures

14

I

4

Back

Close

\section{Full Screen / Esc}

Printer-friendly Version

Interactive Discussion 


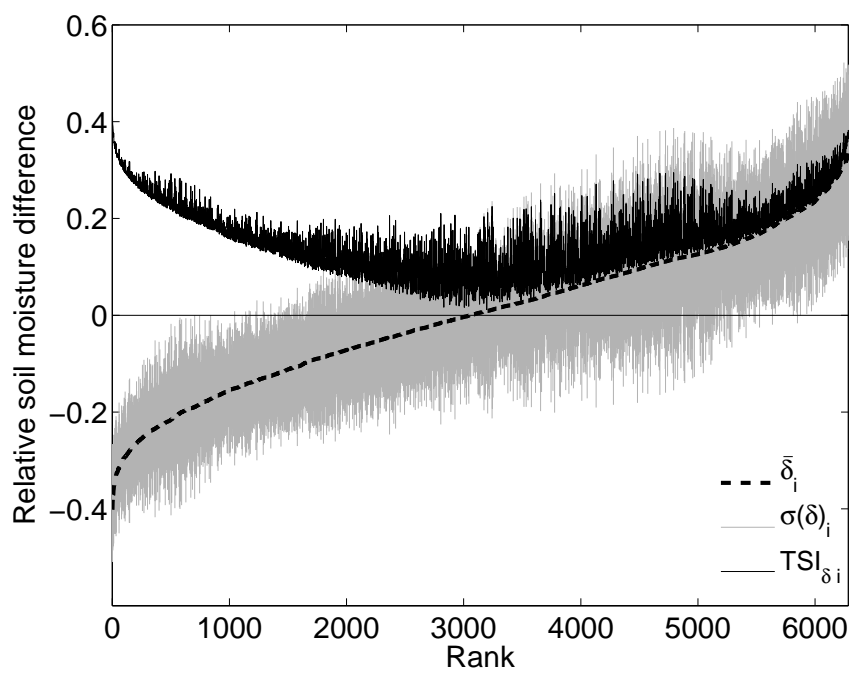

Fig. 7. Rank ordered mean relative difference of GPR-derived soil moisture to the field-average $\bar{\delta}_{i}$ (dashed line) depicted with standard deviation $\sigma\left(\delta_{i}\right)$ (in gray). The temporal stability indicator $\mathrm{TSI}_{\delta_{i}}$ is presented in a plain line.

\section{HESSD}

10, 4063-4097, 2013

Temporal stability of soil moisture patterns

J. Minet et al.

Title Page

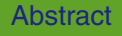

Introduction

Conclusions

References

Tables

Figures

14

4

Back

\section{Full Screen / Esc}

Printer-friendly Version

Interactive Discussion 


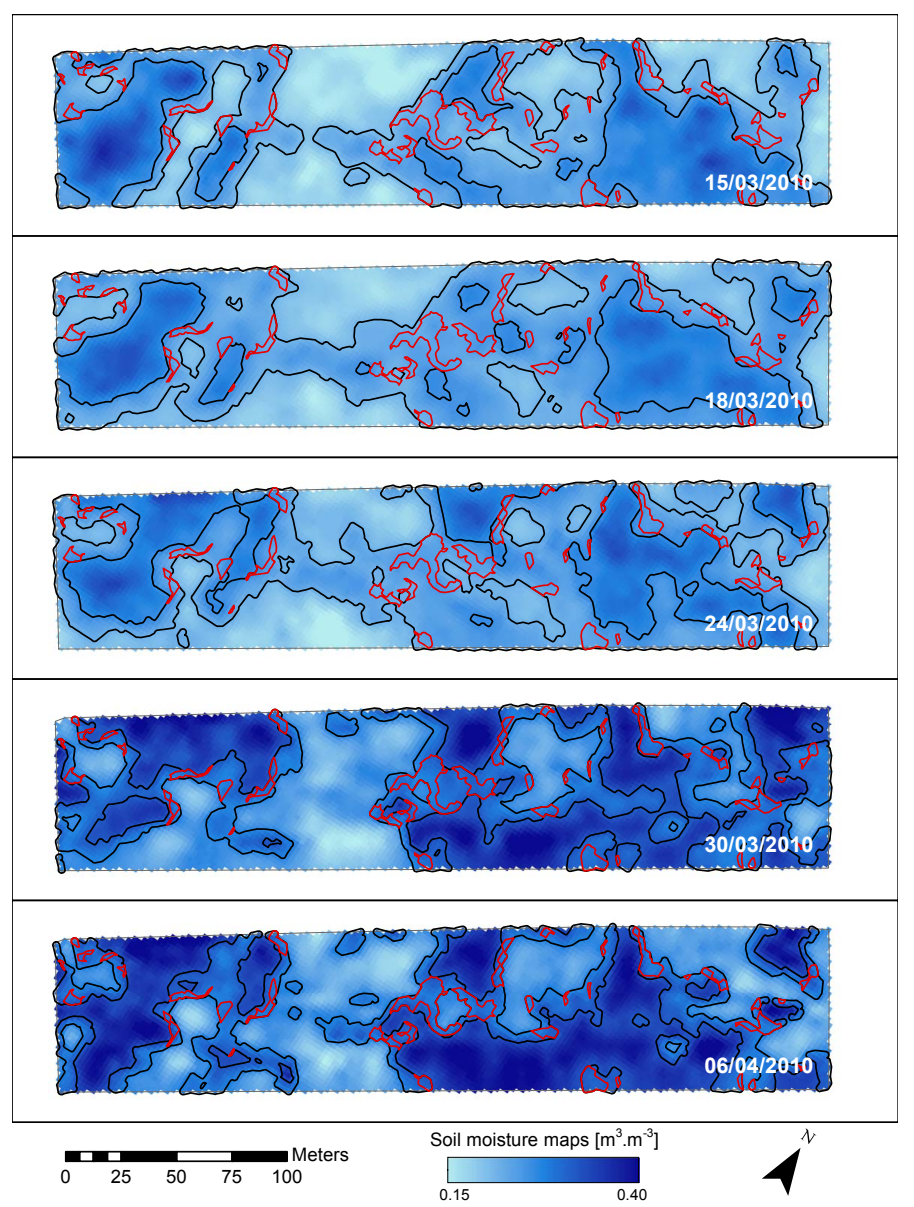

Fig. 8. Soil moisture maps for the five dates. The locations where soil moisture is equal to the field-average within a tolerance of $\pm 0.02 \mathrm{~m}^{3} \mathrm{~m}^{-3}$ are outlined by black lines. The intersection of these zones between the five dates are outlined by red lines (second method).

\section{HESSD}

10, 4063-4097, 2013

Temporal stability of soil moisture

\section{patterns}

J. Minet et al.

\section{Title Page}

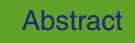

Introduction

Conclusions

References

Tables

Figures

14

4

\section{Back}

Close

\section{Full Screen / Esc}

Printer-friendly Version

Interactive Discussion

(c) (1) 


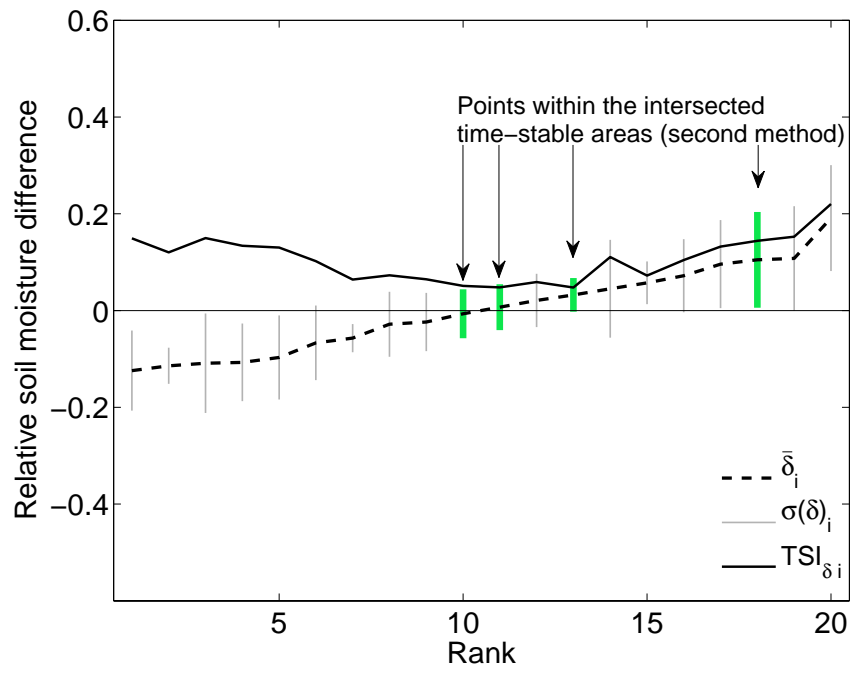

Temporal stability of soil moisture patterns

J. Minet et al.

Title Page

Fig. 9. Rank ordered mean relative difference of volumetric soil moisture to the field-average $\bar{\delta}_{i}$ (dashed line) depicted with standard deviation $\sigma(\delta)_{i}$ (in gray) for the 20 soil core sampling locations. The temporal stability indicator $\mathrm{TSI}_{\delta_{i}}$ is presented in a plain line. Results from soil core sampling measurements.

\section{4}

\section{Full Screen / Esc}

Printer-friendly Version

Interactive Discussion 